\title{
Report on situations and indications for specialist training and undergraduate at status in Europe
}

Francesco Carelli*

Executive Board, EURACT Council, Italy

Many years ago, the Declaration of Alma-Ata defined health as a "complete physical, mental and social wellbeing and not merely the absence of disease or infirmity" and also stated that the access to basic health services was a fundamental human right.

What is the meaning of going back to Alma-Ata now? It leads to an enhancement of the provision of primary care because the challenge for medicine in the third millennium is to achieve the right balance between modern technologies and interpersonal relations. A shift was made, which is characteristic for Family Medicine, from patient to person, from treatment to care given in a network of relationships.

EURACT is stressing the Alma-Ata philosophy, promoting high levels of teaching and health promotion, and looking for mandatory specific training.

Investing in Primary Care, mean to save a lot of money getting the best care for all population.

Doctors are involved in rational decisions, and during their undergraduate and vocational training they need to consider the interrelationships between health and social care, the impact of poverty, ethnicity, inequalities, and the structure of the health care system in which they live and in which they work

European Directives. Since 1993, successive European Directives stated that there would be a vocational training, transformed in specialist training, to become an European Family Doctor. This started with 2 years duration, now is 3 years, in some countries, with different stages, is 4 or 5 years long.

Already in 1998, in Dublin, during WONCA Conference, a WHOWONCA Framework stated that in every University should be a Department of Family Medicine, managed by Family Doctors.

Situation in Europe in different countries is so different and so jeopardized that cannot be done an indication also as groups

As EURACT BME Committee we did a long work ( published : Undergraduate medical education in general practice/family medicine throughout Europe - a descriptive study BMC Medical Education 2013, 13:157) on mapping the European situation. Non to say it was difficult to get a complete list of European Universities in Medicine, each one have different schemes, approaches, attachments. Durations, time of attachments, methodologies, division in periods are so different, that is complicated also dividing Countries with well FM development, medium level and at starting point.

Also, there are strange contradictions, as in some countries where Family Doctors are prepared in Universities' departments, but after that are not such considered in society and in social professional life.
At the extreme it was published an international paper entitled Developing a Mediterranean Family Medicine Group - the Malta Consensus (European Journal of General Practice, Volume 8, June 2002 ) which created great interest for a while.

Key points would be to get the maximum of homogeneity in management and similar curricula so at least to get same international recognition and easier ways to go forward.

In this way, it seems essential to follow the WONCA European Definition, where FM is recognized as a specific discipline, with its own specific field for teaching and for research as the other disciplines. FM is framed in 12 points and in 6 Core Competences specific for Family Doctors. From these competences derive exactly all the FDs' activity in the society. Looking at the European Definition we see what FD is and his/her specific role.

Through EURACT Educational Agenda we have got a big step forward: from ED statements we indicate all the methodology for teaching and learning what should be needed to become a good Family Doctor. This should create the curriculum !

Of course, we need quality and homogeneity to get the best without confusion.

So there is the EURACT Statement on Selection of Teachers and Practice, already modified twice from its original print in 2002. And we have the EURACT Statement on Assessment for learning in Specialty with a needed modern approach where, more than summative assessment, it is the formative assessment to get the continue-key role with a continuous relationship between tutor and trainee. Also another Statement on the topic (ST) went in depth dividing quality in minimum, adequate, excellent level, for trainer as well for practice.

These Documents are cornerstones to create a FD position, curricula, content, methodologies, but also can be used in "politically way " on political tables when different situations and problems appear. So, we have political statement papers:

Crisis and great difficulty was reported in the health care systems of many EU countries at Council Meetings of the European Academy of Teachers in General Practice and Family Medicine (EURACT).

At a time when financial uncertainty and cutting costs are to the fore in many countries, the value of General Practice/Family Medicine as a key part of acceptable, cost effective system was re-underlined

Correspondence to: Francesco Carelli, Executive Board, EURACT Council, Italy, E-mail: francesco.carelli@alice.it

Received: November 07, 2017; Accepted: November 23, 2017; Published: November 27, 2017 
"Health care systems which contain well trained and well supported general practitioners/family doctors consistently deliver best value for money, and better outcomes for individuals, families and communities," Systems which rely on either specialist delivered care, or models which provide fragmented care are neither as effective nor as efficient as systems which maintain well organized Family Practice as the point of first contact for patients accessing healthcare for themselves, and for their families.

"We appreciate that many EU Countries and their citizens are working under very difficult financial pressures, but we urge individual citizens and political leaders to place a value on General Practice and on Family Medicine."

The evidence and international consensus is that continued modest investment in Primary Care delivers major benefits in terms of both population health and the wellbeing of individual patients. Best value is obtained from Euros invested in General Practice/Family Medicine than in any other element of the healthcare system.

Countries and healthcare systems faced with difficult decisions regarding obtaining best value for reduced health care budgets can look to General Practice/Family Medicine with confidence, in terms of delivering real value and good care, at the least cost.

Further adequate investments in General Practice/Family Medicine are also necessary to enable it to develop its full potential and to prevent an increasing use of hospital based care and General Practice/Family Medicine can deliver real solutions in stressed healthcare systems, throughout Europe

It is in act an increasing division of care on different providers, which would cut family doctor-patient continuity and relationship and in this way would lead to higher cost.

"Many of us engaged in General Practice/Family Medicine Teaching might be tempted to feel discouraged by the uncertainty and stresses faced by our Patients, but this is arguably a time when the discipline of General Practice, driven by science and compassion rather than money and profit, can really shine."

Moreover, the EURACT Council is worried explicitly about the way EU regulations concerning the Undergraduate and Post-graduate specialty training of Family Physicians is neglected or disrespected in some European countries, concerning selection of teachers, students and trainees, as well as General Practice/Family Medicine curricula. We therefore ask for the attention of all members of the European Parliament and other national governments EU structures and other stakeholders for this matter (EURACT Website).

Specific letters were sent to Ministries of Austria and of Latvia when, in first case they were cancelling trainees' attachments during specialist training, in second case were promoting as Family Doctors all doctors after just a week long course.

In the same way was published an EURACT Statement on Family Medicine Undergraduate Teaching in all European Universities. This statement was drawn up by the Basic Medical Education Committee of EURACT.

Taking into account Council Directive 93/16/EEC to facilitate the free movement of doctors, the European Credit Transfer System, UEMO Policy Paper on Specific Training in GP/FM, Framework for Professional and Administrative Development of GP/FM in Europe, considering Bologna declaration, bill of patient rights and other documents on education and training in higher education as WHO -WONCA Framework published in 1998, and confirmed in series of documents from EU Commissions, Colleges, Academies, remembering Alma Ata declaration on the role of primary care, EU orientation in strengthening primary care,

EURACT states that each University medical School educating future medical doctors must offer all students adequate level of knowledge, practice and exposure to family practice care to gain knowledge, skills, attitudes and scope of primary care approach. To achieve these goals this statement intends to provide guidance how to tailor existing or how to introduce teaching and training in General Practice/Family Medicine (GP/FM) in all European Universities. It is not intended to be a detailed and exhaustive description of the content of teaching curricula as these should be, of necessity, context specific and will depend on the tasks that GP/FM doctors are expected to undertake in different countries. Nevertheless a core European content as coming from the WONCA European Definition, as well as it cannot forget content as detailed in EURACT Educational Agenda, which are applicable universally.

\section{Introduction}

As indicated in WHO - WONCA Framework published in 1998, and confirmed in series of documents from EU Commissions, Colleges, Academies (not to say EURACT) every Faculty of Medicine must create a Department of Family Medicine managed by qualified and selected general practitioners/family doctors. At the same time there must be a training to take place in the GP/FM setting, where the student encounters patients who are representative of GP/FM practice populations. This teaching and training are recognized as a "must" in all modern societies: medical students cannot become future good doctors without knowing family medicine context; family medicine is the keystone for economic welfare, quality and costs.

Teachers in GP/FM practice must be qualified general practitioners/ family doctors, selected according to clear and open criteria as described in the EURACT Statement for Selection of Teachers and Practice in GP/FM.

Medical Students also need to acquire specific competencies that are most easily obtained in a general practice setting. These competencies have been clearly outlined by Wonca (World Organization of Family Doctors) in the "Checklist for Family Medicine/General Practice Experiences" and could be grouped in two categories:

- management of patients and conditions that are frequently seen in GP/FM, essential for competence with regard to diagnosis, prognosis and appropriate treatment;

- development of skills and attitudes specific and necessary as future GP/FM practitioners.

Based on the European society development, it is urgent and not avoidable necessity to set down principles that ensure these teaching and training would be finalized and with the required quality and relevance for future family doctors for the best of the European population.

\section{Key principles}

Considering EURACT Mapping of Undergraduate Teaching of Family Medicine in Europe (showing in detail, who is in delay or worse), considering EURACT BME Committee's work and publication on an European Minimal Core Curriculum for teaching 
Family Medicine (indicating the line to be followed to get an essential and key homogeneity, so to help, avoid resistances, avoid confusion) these are the key principles.

1. Each University Medical School should have fully integrated and operational a Department of Family Medicine/General Practice, starting with undergraduate training as a part of the process of obtaining a level of clinical competence sufficient for independent practice

2. Family Medicine/General Practice Curriculum for undergraduate education should be developed in collaboration with Family Medicine/General Practice departments and Medical Professional Organizations in the country. International collaboration among Departments which present a success story in the development of the discipline could be sought.

3. Family Medicine/General Practice Curriculum should be based on European Definition of General Practice and Educational Agenda. National specifics on organisation and delivery of health care on primary care level and collaboration across the interface between primary and secondary care should be appropriately included.

4. Based on UEMO policy statement on specific training, a minimum of $50 \%$ of training should be in general practice, starting with undergraduate training as a part of the process of obtaining a level of clinical competence sufficient for independent practice

5. All students should be able to learn primary care management of patients through a student clerkship in general practice, lasting several weeks during the later years of medical school.
6. What about this? There should be a minimal curriculum with minimum of credits across more than just one (last) semester. Lectures should be delivered by family physicians/general practitioners and limited to core themes proposed by EURACT and national associations of family physicians/general practitioners. The majority of programme should be in small group work and in one to one teaching in family physicians'/general practitioners' practices.

7. The chairs of the departments must be doctors with appropriate academic achievements as other department chairs in the particular University. A lack of academic achievements should be overcome by assigning a family physician/general practitioner to co-chair a department for a defined transition period.

\section{(EURACT Website )}

Another key point is to get similar curricula and contents:

For Specialist Training would be to follow the indications as written in EURACT Educational Agenda. For Undergraduate level, a paper was written by EURACT BME Committee, following a Delphy Method, where are indicated the first 15 subjects to be taken in account in an undergraduate attachment Minimal Core Curriculum. (European Journal of General Practice, 2011; 17: 217-220 ).

Many National Societies and Academies has written documents concerning Primary Care role, one of the best developed is the German DEGAM. 